\title{
Preoxygenation in Critically Ill Patients Requiring Intubation: Difficult Questions, No Easy Answers
}

Airway management in critically ill patients remains a fundamental but challenging procedure, characterized by a high rate of complications. Studies have shown that as many as $40 \%$ of intubations in critical care settings are accompanied by severe adverse events, ${ }^{1,2}$ the most frequent complication being hypoxemia. A prospective study from critical care units in Scotland reported that severe hypoxemia $\left(\mathrm{S}_{\mathrm{pO}_{2}}<80 \%\right)$ during endotracheal intubation occurred in $22 \%$ of subjects, despite the procedure being carried out by highly skilled teams. ${ }^{3}$ Patient factors, expertise of the intubating clinician, choice and dose of induction and neuromuscular blocking drugs, and pre-induction management all contribute to safety and outcome. ${ }^{3}$ In the operating room, one crucial step to minimize desaturation during intubation is preoxygenation by administering high oxygen concentration via face mask. Unfortunately, preoxygenation of critically ill patients is less effective. ${ }^{4,5}$

Different techniques for preoxygenation have been investigated in the intensive care setting. Tightly fitting bag-valve-mask proved to be only marginally effective., ${ }^{4,6}$ Noninvasive ventilation delivered via face mask for a 3-min period pre-intubation appears to aid in reducing arterial oxyhemoglobin desaturation during the procedure, ${ }^{7}$ although no large randomized trials have confirmed these findings. A limitation of this technique is that its use must be interrupted during laryngoscopy, reducing the benefits, and this may account for its frequent failure to prevent desaturation. In recent years, high-flow nasal cannula (HFNC) has gained attention in critical care due to its capacity to generate positive airway pressure, using a small interface and heated and humidified air flow, providing greater comfort than traditional oxygen therapy. ${ }^{8}$ These features make it an attractive candidate for improving preoxygenation as well as maintaining apneic oxygenation

Dr Cooper has disclosed a relationship with Verathon. Dr Parotto has disclosed no conflicts of interest.

Correspondence: Matteo Parotto MD PhD, Department of Anesthesia, University of Toronto and University Health Network, Toronto General Hospital, 3EN-429, 200 Elizabeth Street, Toronto, Ontario M5G 2C4, Canada. E-mail: matteo.parotto@uhn.ca.

DOI: $10.4187 /$ respcare. 05091 during intubation attempts in the critically ill. MiguelMontanes et $\mathrm{al}^{9}$ compared non-rebreathing bag reservoir face mask with HFNC for preoxygenation before endotracheal intubation of intensive care subjects with mild to

See the Original Study on Page 1160

moderate hypoxemia. Their single-center, before-after study showed that the HFNC group maintained higher $\mathrm{S}_{\mathrm{pO}_{2}}$ during intubation and experienced a significantly lower prevalence of desaturation events $(<80 \%)$ compared with the face mask group. ${ }^{9}$ Their findings were not confirmed by a multi-center randomized controlled trial, where Vourc'h et al ${ }^{10}$ compared HFNC with high-flow facial bag-valve-mask for preoxygenation (and apneic oxygenation) in severe hypoxemic subjects and found no difference in the median lowest saturation throughout the intubation procedure.

In the current issue of Respiratory CARe, Simon et al ${ }^{11}$ studied 40 average-sized adult subjects (mean body mass index 25 and 27) with relatively mild hypoxemic respiratory failure, lacking features predictive of a difficult intubation, randomized to receive preoxygenation by HFNC at $50 \mathrm{~L} / \mathrm{min}$ or by bag-valve-mask. Following a rapid sequence protocol, intubation was quickly accomplished in all subjects by direct laryngoscopy, performed by critical care specialists, $1 \mathrm{~min}$ after administering rocuronium. During apnea, oxygenation was by HFNC or application of a face mask without positive pressure. They assessed oxygenation before and $1 \mathrm{~min}$ after rocuronium as well as immediately before and at intervals following the institution of positive pressure ventilation. After $1 \mathrm{~min}$ of apnea, but before intubation, there was a significant decrease in the $\mathrm{S}_{\mathrm{pO}_{2}}$ in the bag-valve-mask but not in the HFNC group. Five subjects in each group experienced oxygen desaturation $<80 \%$, resulting in abandonment of apnea and conversion to emergency intubation in 2 subjects in each group. However, there was no significant difference between the 2 groups in the primary outcome: the lowest oxygen saturation between induction and recovery following positive pressure ventilation. Not reported, but important, laryngoscopy was initiated at $1 \mathrm{~min}$ following rocuronium administration, and intubation was successful on the first 


\section{Preoxygenation in the CRitically Ill}

attempt in every subject (personal communication, 2016, Marcel Simon MD, University Medical Center HamburgEppendorf, Hamburg, Germany).

Their findings are consistent with those from Vourc'h et al. ${ }^{10}$ As the authors point out, one of the potential reasons for the difference between these 2 trials and the before-after study by Miguel-Montanes et $\mathrm{al}^{9}$ could reside in part in the fact that subjects previously receiving noninvasive ventilation or HFNC were not included in the latter, whereas $28 \%$ of subjects in the Simon et al study ${ }^{11}$ and $27 \%$ of those in the Vourc'h et al study ${ }^{10}$ had been receiving noninvasive ventilation. Differences in severity of hypoxemia as well as indication for intubation might have also played a role.

Another trial evaluated the effect of supplemental oxygenation by HFNC during laryngoscopy (vs no oxygenation) in 150 critically ill subjects and reported no difference in the median lowest arterial oxygen saturation, incidence of oxygen desaturation $<90$ or $<80 \%$, or decrease in oxygen saturation $>3 \%$ from baseline. Of note, in this study by Semler et al, ${ }^{12}$ the oxygen flow via HFNC was limited to $15 \mathrm{~L} / \mathrm{min}$, much lower than what was used in the trial from Simon et al, ${ }^{11}$ who set the $\mathrm{HFNC}$ at $50 \mathrm{~L} / \mathrm{min}$.

There are several details that may account for the apparently limited benefit from HFNC preoxygenation. Simon et al ${ }^{11}$ excluded patients likely to be difficult to intubate, and thus the apneic period was brief. In the practice of critical care, we lack such a luxury. Frequently, intubation efforts are prolonged or repeated, placing hypoxemic patients at greater risk. ${ }^{13}$ If confirmed in such scenarios, the observation of a significant decrease in the $\mathrm{S}_{\mathrm{pO}_{2}}$ during the apnea phase before intubation in the bag-valve-mask but not in the HFNC group could indeed be of great relevance. Simon et al ${ }^{11}$ make no mention of whether a jaw thrust, mouth closure, or head-of-bed elevation positioning were employed, all of which may enhance the value of HFNC. ${ }^{14}$

Despite its attractive features, the role of HFNC in this setting has yet to be clearly established. To the extent that apnea may be prolonged and associated with a greater risk of hypoxemia, a preoxygenation (or continuous oxygenation) strategy associated with low risk and improved outcomes is clearly desirable. It remains to be determined whether patients at such risk can be reliably predicted and whether HFNC or noninvasive ventilation can provide protection against oxygen desaturation. Further data with highrisk representative patients optimizing the use of the techniques are warranted.

In the meantime, clinicians will continue to vigilantly approach intubation of the critically ill to minimize hypoxemia-related complications, ensuring adequate expertise and/or expert supervision, using optimal techniques (eg, videolaryngoscopy as a primary plan), ${ }^{15}$ emphasizing first-attempt success, ${ }^{16}$ and carefully considering the specific merits of sedation and muscle relaxation versus topical anesthesia and maintenance of spontaneous breathing. ${ }^{17}$ The journey toward making this high-risk procedure safer continues.

\section{Matteo Parotto MD PhD Richard M Cooper MSc MD} Department of Anesthesia University of Toronto and University Health Network Toronto General Hospital Toronto, Ontario, Canada

\section{REFERENCES}

1. Jaber S, Amraoui J, Lefrant JY, Arich C, Cohendy R, Landreau L, et al. Clinical practice and risk factors for immediate complications of endotracheal intubation in the intensive care unit: a prospective, multiple-center study. Crit Care Med 2006;34(9):2355-2361.

2. Griesdale DEG, Bosma TL, Kurth T, Isac G, Chittock DR. Complications of endotracheal intubation in the critically ill. Intensive Care Med 2008;34(10):1835-1842.

3. Simpson GD, Ross MJ, McKeown DW, Ray DC. Tracheal intubation in the critically ill: a multi-centre national study of practice and complications. Br J Anaesth 2012;108(5):792-799.

4. Mort TC. Preoxygenation in critically ill patients requiring emergency tracheal intubation. Crit Care Med 2005;33(11):2672-2675.

5. Farmery AD, Roe PG. A model to describe the rate of oxyhaemoglobin desaturation during apnoea. Br J Anaesth 1996;76(2): 284-291.

6. Mort TC, Waberski BH, Clive J. Extending the preoxygenation period from 4 to 8 mins in critically ill patients undergoing emergency intubation. Crit Care Med 2009;37(1):68-71.

7. Baillard C, Fosse JP, Sebbane M, Chanques G, Vincent F, Courouble $\mathrm{P}$, et al. Noninvasive ventilation improves preoxygenation before intubation of hypoxic patients. Am J Respir Crit Care Med 2006; 174(2):171-177.

8. Papazian L, Corley A, Hess D, Fraser JF, Frat JP, Guitton C, et al. Use of high-flow nasal cannula oxygenation in ICU adults: a narrative review. Intensive Care Med 2016 [Epub ahead of print] doi: 10.1007/s00134-016-4277-8.

9. Miguel-Montanes R, Hajage D, Messika J, Bertrand F, Gaudry S, Rafat C, et al. Use of high-flow nasal cannula oxygen therapy to prevent desaturation during tracheal intubation of intensive care patients with mild-to-moderate hypoxemia. Crit Care Med 2015;43(3): 574-583.

10. Vourc'h M, Asfar P, Volteau C, Bachoumas K, Clavieras N, Egreteau PY, et al. Highflow nasal cannula oxygen during endotracheal intubation in hypoxemic patients: a randomized controlled clinical trial. Intensive Care Med 2015;41(9):1538-1548.

11. Simon M, Wachs C, Braune S, de Heer G, Frings D, Kluge S. High flow nasal cannula oxygen versus bag-valve-mask for preoxygenation before intubation in patients with hypoxemic respiratory failure: a randomized controlled trial. Respir Care 2016;61(9):11601167.

12. Semler MW, Janz DR, Lentz RJ, Matthews DT, Norman BC, Assad TR, et al. Randomized trial of apneic oxygenation during endotracheal intubation of the critically ill. Am J Respir Crit Care Med 2016;193(3):273-280.

13. Adnet F, Borron SW, Racine SX, Clemessy JL, Fournier JL, Plaisance P, Lapandry C. The intubation difficulty scale (IDS): proposal 
and evaluation of a new score characterizing the complexity of endotracheal intubation. Anesthesiology 1997;87(6):1290-1297.

14. De Jong A, Jaber S. Apneic oxygenation for intubation of the critically ill: let's not give up! Am J Respir Crit Care Med 2016;193(3): 230-232.

15. De Jong A, Molinari N, Conseil M, Coisel Y, Pouzeratte Y, Belafia F, et al. Video laryngoscopy versus direct laryngoscopy for orotra- cheal intubation in the intensive care unit: a systematic review and meta-analysis. Intensive Care Med 2014;40(5):629-639.

16. Natt BS, Malo J, Hypes CD, Sakles JC, Mosier JM. Strategies to improve first attempt success at intubation in critically ill patients. Br J Anaesth 2016 [Epub ahead of print] doi: 10.1093/bja/aew061.

17. Lapinsky SE. Endotracheal intubation in the ICU. Crit Care 2015; 19:258. 